\title{
Elevate Project Success Rate with Right Judgement of Complexity and Skill Competency Gap
}

\author{
Thejasvi N, Shubhamangala B R
}

\begin{abstract}
Software project management constantly keep fighting triple constraint of Quality, Schedule and Time. Failures are due to poor visibility of Project complexity and incorrectly estimating right skilled team. The project success rates are constantly falling in spite of implementing various project management principles involving waterfall, Scrum, Scaled Agile framework (SAFe), etc. The approach taken to estimate the team composition are based on non-contextual, unscientific methodology based on previous project experiences by the team. As our study found that, every organization had its unique approach to derive root cause of their failures and had custom-built estimation templates. A deep-rooted empirical research is under taken here addressed around three Capability Maturity Model (CMM) level 5 organizations. Often complexity is under-estimated and this is the enemy of software estimation. If this hypothesis is right, complexity metric can forecast the depth of estimation challenges and can help in prioritizing task and various intricate efforts needed and thereby deduce the appropriate team to navigate toward project success.
\end{abstract}

Our Research was under taken in below two phases:

Phase I - To investigate and address poor project complexity definition through quantification of project complexity

Phase II - To derive metric around skill-capability Index in conjunction with project complexity.

In Phase I, interviews and deliberation techniques were leveraged involving senior software practitioners. In Phase II, evaluation of the unsuccessful projects from the initiation until operational stage was carried out.

Combining the phase I and II results, overall reasons contributing to incorrect mapping of skilled staffing was found.

This paper presents two research contributions, firstly an approach to uncover poor estimation of skilled staff for a project with correct complexity mapping, secondly skill-competence index in line with project complexity quantification as a multi-dimensional solution to overcome project failures. Proposed model was found to be productive in real projects; in addition, the results showed that complexity metric estimated with this unique approach had low false positive rate and minimal deviations in project outcomes.

Keywords: Project complexity; Project Failure; Project Evaluation; Skill-Capability Index.

\section{INTRODUCTION}

Today's enterprises bet their growth on digital platforms to run their business models, Information Technology (IT) industry has a tremendous pressure to sustain in midst of resourcing at scale, staying relevant with niche technologies, branding, market sensitive pricing with healthy operational profit margins year on year, these challenges have been compounded further with niche competitors in the market. Software integrators and vendors have recognized that project

Revised Manuscript Received on November 15, 2019

Thejasvi N, Computer Science and Engineering, Jain University, Bengaluru, India.

Dr.Shubhamangala B R, Professor, Research Head, Bengaluru, India. success and higher engagement level feedbacks are quintessential to stay relevant to their customer-base. The chances of staying relevant further depends on the supplementary facts such as Agility, flexibility, maximizing return on investment with value addition, and narrating the benefits amongst IT and business. In the present competition in the software servicing industry, meeting growth aspirations has become extremely challenging due to project failure and customer frustration majorly caused due to increased end customer demands, poor estimation, lack of clear understanding of project scope and complexity. Hence matured organizations have taken various quality gating processes, inculcated Due-diligence and formal knowledge transfer (KT) process as part of commencing any new engagement to understand AS-IS landscape, and look at TO-BE IT estate and accordingly derive the correct level of understanding around scope, complexity, technology needs, Infrastructure, logistics, etc. Despite persistent efforts, IT industry is able to achieve up to 5\% improvement only and is facing the recurrence of similar issue. Software firms are unable to systematize project complexity domain as it is intertwined with clients, technology, business domain, of the enterprise. Assessing the project complexity with reference to similar case studies in the past and retrospections from previous engagements can only help to some extent to cover for the estimation but largely each customer IT estate varies from the other. Above discussed industry, challenge directs a need of deeper research to focus around project failures arising primarily due to complexity and skill-estimation domains. Assessing the project complexity and estimating right staffing is a human centric activity. Deeper analysis is needed to understand the abstract problem statements generally available at the project commencement phases. We have innovated a technique to quantify the project complexity and thereby derive the skill-capability matching index to arrest project failures commonly occurring due to misjudgment of scope and complexity. Hopeful results were observed when this technique was applied to software projects under study.This paper is structured in two parts in-line with two-phase approach adopted in our research study. First part discusses project complexity assessment whereas second part discusses skill-matrix index. Section II and III deals with problem statement and research methodology of project complexity. Section IV discusses findings of the same. Section V and VI presents problem statement and research methodology around skill-index. Section VII highlights findings around skill-competence framework. Section VIII shares the results, Section IX and X discusses and concludes. 


\section{Elevate Project Success Rate with Right Judgement of Complexity and Skill Competency Gap}

\section{PROBLEM STATEMENT (PHASE 1)}

Referencing to the Standish group report [2] though a great number of clients express satisfaction in their project outcomes, a deeper analysis exposes cracks in the otherwise decently satisfying picture. As a matter of fact, $29 \%$ of all the projects were thriving success i.e. delivered on budget, on time with passable features; $52 \%$ challenged (late, over budgeted, less than estimated functions and features); $19 \%$ cancelled (client dissatisfaction, feature never used)

$\begin{array}{llll} & 2013 & 2014 & 2015 \\ \text { SUCCESSFUL } & 31 \% & 28 \% & 29 \% \\ \text { CHALLENGED } & 50 \% & 55 \% & 52 \% \\ \text { FAILED } & 19 \% & 17 \% & 19 \%\end{array}$

SUCCESSFUL CHALLENGED FAIL

$\begin{array}{llll}\text { GRAND } & 2 \% & 7 \% & 17 \% \\ \text { LARGE } & 6 \% & 17 \% & 24 \% \\ \text { MEDIUM } & 9 \% & 26 \% & 31 \%\end{array}$

MODERATE $21 \% \quad 32 \% 17 \%$

SMALL $\quad 62 \% \quad 16 \% 11 \%$

(ALL Projects) SUCCESSFUL CHALLENGED FAIL

$\begin{array}{lllr}\text { Agile } & 39 \% & 52 \% & 9 \%\end{array}$

$\begin{array}{llll}\text { Waterfall } & 11 \% & 60 \% & 29 \%\end{array}$

Our research is focused on the current industry challenges with latest delivery methodologies:

- Why do considerable Agile Projects (specifically SAFe projects) fail due to incorrect assessment of project scope and complexity in spite of implementing SAFe agile principles? This hints at 'Lack of Project complexity concept in SAFe Agile'

- What feasible techniques could be adopted to assess the true project complexity and thereby derive skill-capability index, which can elevate the project success rate? - Lack of Project complexity concept in SAFe Agile needs to be addressed.

Our research intends to seek answers to below:

Q1: Can a complexity metric for estimation domain cater to latest cloud or Commercial off the shelf (COTS) technology as these are todays IT trend?

Q2: Can we derive the depth of skill-set needed in Estimation functions using complexity metrics? If yes, can it be applicable for development as well as configuration tasks?

Q3: Can we identify the key complexity levers in the project, and there by prioritize the tasks using complexity metrics?

Answering above first and third question helps prioritize the focus areas in term of expected efforts; Answering Q2 helps to determine scale of each skill-set which is often seen as the cost-lever, but a sure failure point or root cause of customer dissatisfaction in many projects.

\section{RESEARCH METHODOLOGY (PHASE 1)}

Our research is executed in two phases. The first phase explores inherent factors around poor project complexity understanding and other biased assumptions. Formal and informal interviews, discussions were leveraged. Specialists were consulted.

Discussions revealed serious issues in the AS-IS IT ecosystem understanding and inherent challenges in getting all the required inputs owing to inadequate documentation and absence of system specialists.

Project studied are as given in table 1 below.

\section{Tab-1: Engagement level feedback with cost overrun}

\begin{tabular}{|c|c|c|c|c|}
\hline $\begin{array}{l}\text { TABLE 1: } \\
\text { PROJECTS } \\
\text { STUDIED } \\
\text { Projects } \\
\text { from } \\
\text { company }\end{array}$ & $\begin{array}{l}\text { No of } \\
\text { Projects }\end{array}$ & $\begin{array}{l}\text { Project } \\
\text { methodolo } \\
\text { gy }\end{array}$ & $\begin{array}{l}\text { Engagem } \\
\text { ent level } \\
\text { feedback } \\
\text { (around } \\
\text { Estimates } \\
\text { in scale of } \\
7 \text { ) }\end{array}$ & $\begin{array}{l}\text { Cost } \\
\text { over } \\
\text { Run } \\
\text { in \% }\end{array}$ \\
\hline $\mathrm{C} 1$ & 2 & $\begin{array}{l}\text { SAFe } \\
\text { Scrumban }\end{array}$ & 6 & 10 \\
\hline $\mathrm{C} 2$ & 1 & $\begin{array}{l}\text { Agile } \\
\text {-scrum }\end{array}$ & 5.5 & 12 \\
\hline C3 & 2 & $\begin{array}{l}\text { SAFe } \\
\text { Scrum }\end{array}$ & 6.2 & 25 \\
\hline
\end{tabular}

Standard Engagement Feedback reference scale as below [9]: Feedback is to evaluate performance, on key aspects (Product, Management, People, Communication, and Value-Differentiation).

\begin{tabular}{|l|c|c|c|c|c|c|c|c|}
\hline \multirow{2}{*}{$\begin{array}{l}\text { RATING } \\
\text { SCALE }\end{array}$} & NA & 1 & 2 & 3 & 4 & 5 & 6 & 7 \\
\cline { 2 - 8 } & $\begin{array}{c}\text { Not } \\
\text { Applicable }\end{array}$ & $\begin{array}{c}\text { Extremely } \\
\text { Dissatisfied }\end{array}$ & $\begin{array}{c}\text { Very } \\
\text { Dissatisfied }\end{array}$ & Dissatisfied & $\begin{array}{c}\text { Neither } \\
\text { Dissatisfied } \\
\text { Nor Satisfied }\end{array}$ & Satisfied & $\begin{array}{c}\text { Very } \\
\text { Satisfied }\end{array}$ & $\begin{array}{c}\text { Extremely } \\
\text { Satisfied }\end{array}$ \\
\hline
\end{tabular}

As indicated in table 1, SAFe Agile projects are taken for study. Engagement level feedback and budget overrun details of these projects were also considered. Evaluations of these five projects were carried out from the commencement stage until post-go live stage by studying the comprehensive project report.

Below phase-wise project evaluation was taken up:

1. Inception phase Evaluation

1. In-flight projects Evaluation

2. Retrospection phase Evaluation

3. Project exit Evaluation

Evaluation is focused on Key Process Indicators (KPI) pertaining to estimation and engagement level feedback. In pre-project evaluation the scope, AS-IS and TO-BE IT architecture, technology, etc are observed. In In-flight project evaluation, major \& minor release deliverables were examined (e.g., Feature level estimates, capability estimates, Solution reuse estimate). In project completion retrospection the features of project such as percentage of change request, scope overflow, rework, committed roadmap budget variance, country rollout cost, stakeholder feedback in sprint demos, cost variation, schedule overrun, defect density, peer productivity average, etc were studied.

\section{FINDINGS}

Right from the presales engagement till signing of statement of work, there exists a gap

between actual customer needs versus stated requirements due to lack of understanding of true complexity of as-is or to-be application landscape. Understanding of the client needs when built on heavy forward-looking assumptions and incompleteness due to the vague requirements stated in natural language are often compounded by absence of process specialist or technical analyst thus leading to superficial foundations [1][3] for future scope of work. These are further worsened due to lack of access to AS-IS demo systems or original documentations. This superficial AS-IS and TO-BE business process and IT architecture snapshot [3] knowledge leads to misguided 
staffing seldom associated with missed technology levers thus causing project failures. Lack of sufficient system appreciation is a major problem (Inception Phase Evaluation). True system complexity and technical inter-dependencies are not captured, leading to faulty appreciation of the system, which is being taken over for further support, and enhancements in a managed services kind of implementations. Comprehensiveness and correctness of project scope and true complexities are not always corroborated, plus absence of suitable metric to assess the accuracy leads to incorrect estimates and staffing. As part of statement of work or engaging with new customer one of the popular models among the organizations interviewed revealed that senior industry skilled core team is utilized as a light house team to take up AS-IS system appreciation and document the current technology stack and call out upto Level 3 business processes. The output from this team comprises scope, technology width, process map, next knowledge transfer team structure, skill-set mix, competence level, logistics and so on. The lighthouse team cannot call out system complexity nebulously, rather they will have to undertake systematic study and utilize third party tools and accelerators to parse the system boundary and document the composition of the current system in question.

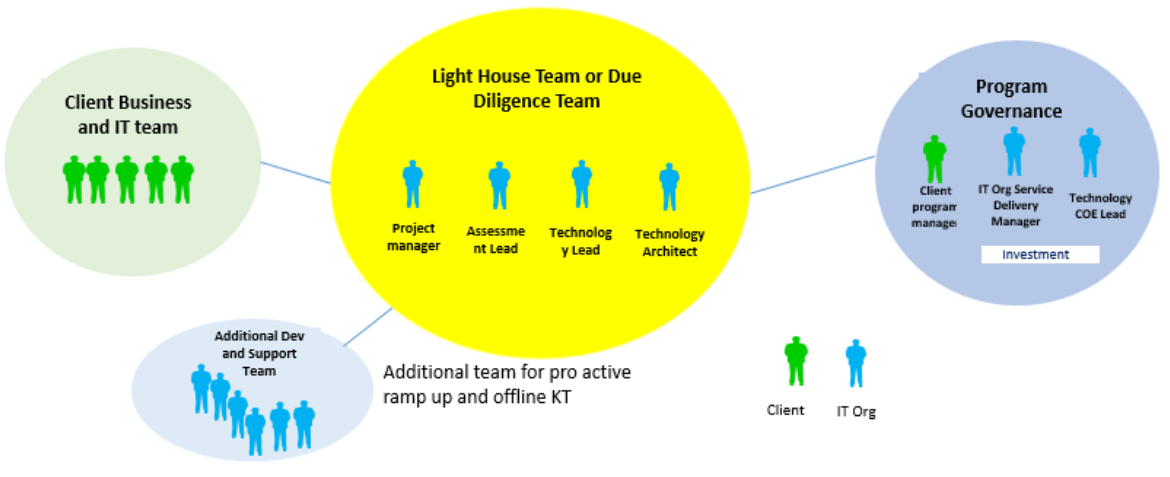

Fig-1: Lighthouse Due Diligence Team structure

The Due-diligence team can bucket the study into various technology levers or skill-set base; a popular Red-Green-Yellow (RGY) model can be adopted to reflect the current health of the system (i.e. Red indicating complex, not-well managed, risky; Green indicating Good status of the system in all counts; Yellow reflecting needing immediate attention before the subject area slips to red)

\section{Tab-2: Sample System appreciation breakdown}

\begin{tabular}{|l|l|}
\hline \multicolumn{1}{|c|}{ PARAMETERS } \\
\hline$\square$ & Level of customizations \\
\hline$\square$ & Code Quality \\
\hline$\square$ & User Interface \\
\hline$\square \quad \begin{array}{l}\text { User, Permission / Role } \\
\text { management }\end{array}$ & \\
\hline$\square$ & $\begin{array}{l}\% \text { of usage of standard } \\
\text { features }\end{array}$ \\
\hline$\square$ & $\begin{array}{l}\text { Data and code } \\
\text { redundancies }\end{array}$ \\
\hline$\square$ & $\begin{array}{l}\text { Configuration } \\
\text { (Workflow, Validation } \\
\text { and process builder ) }\end{array}$ \\
\hline
\end{tabular}

In the typical parameters associated with any given project, the most effort consuming aspect is Customization (Coding), even the T-shirt sizing principles in Agile world will look at build effort and then extrapolate it to cover other Software Development Life Cycle (SDLC) life cycle.

The Customization bucket includes Coding, Integration, NFR Tuning and other skilled and technology intensive work; which forms the key basis for estimation. The development estimates (utilizing methodologies such as Function Point, Package Points, etc.) itself plays a pivotal role in success or failure of a given project. Estimating right number of developers, right skill-mix, right depth / scale of skill is the key to get the appropriate team composition for a given project. In below study, we see how Complexity Metric and study categorization can be directly referred to get right justifiable development estimates and map to the right skill-set scale to achieve optimal balance in the proposed project team. 


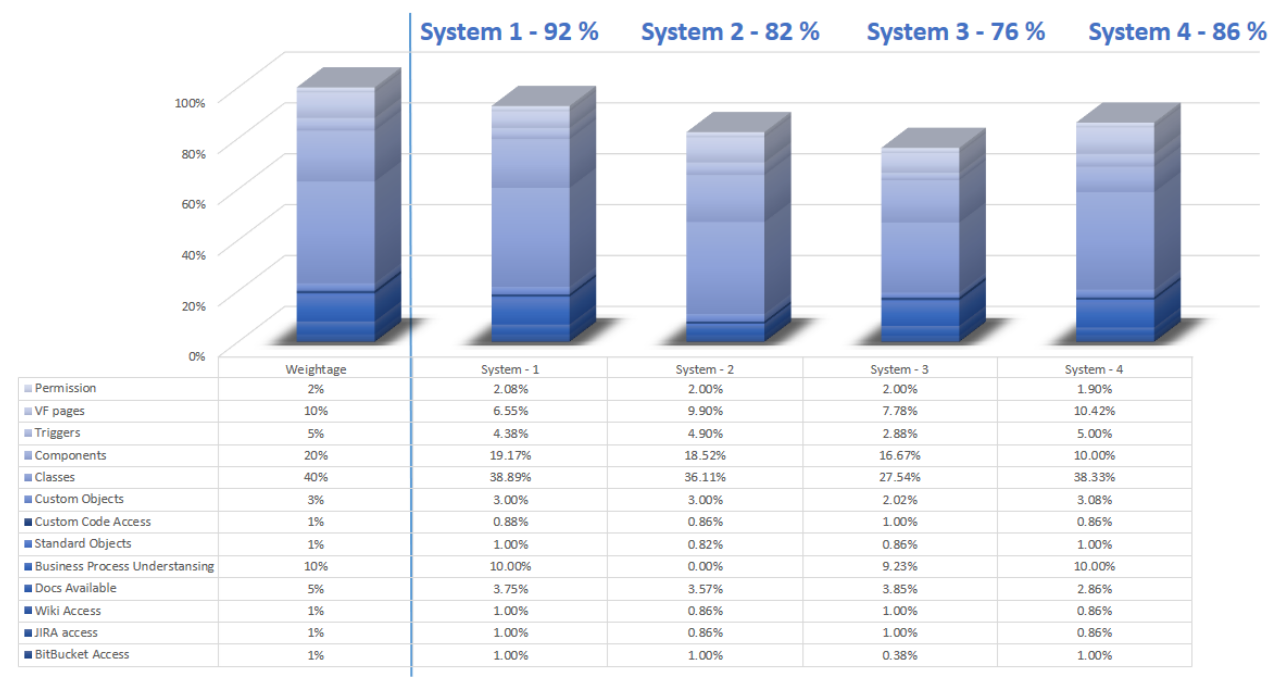

Fig - 2: Knowledge transfer status (AS-IS) in typical CRM project involving large-scale multi-country rollout.

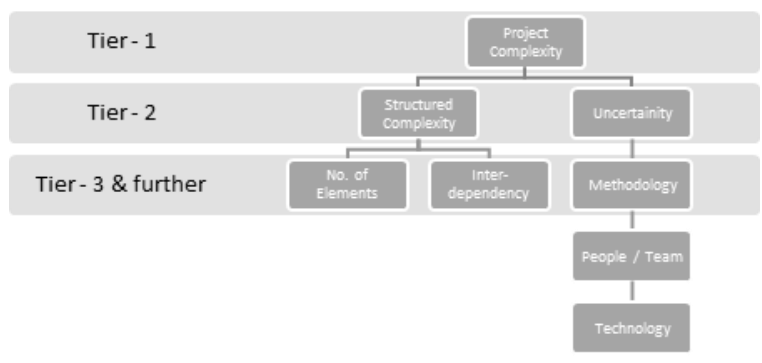

Fig - 3: Typical Project complexity structure

\section{Metrics}

McCabe's cyclomatic complexity [8] adds a factor 1 on top of number of decision statements in a given program.

Cyclomatic complexity gives quantitative scoring of a code structure by counting its complexity at primitive single statement level. A given code is iteratively parsed to derive the total count per method. Within each method number of paths are counted, lines of codes are counted without comments, exe count is without declarations, nesting count is derived through deepest nested level construct, so on.

\section{Project under study}

We have chosen a cloud based Customer Relationship Management (CRM) implementation for our case study because the cloud offering suits allows free subscription upto a year and its free for developer and research (non-commercial) use. Cloud technology also is in-line with latest IT trend. We have chosen a sample free-form project available for a typical telecom domain with e-Telecom Operational Map model implementation. For diversity reasons a telecom CRM implementation, manufacturing industry CRM implementation and a beverage industry CRM application have been chosen.

Implementation of algorithm in Object oriented programming (OOPs) language -

Mccabe's complexity algorithm follows a scanning technique to cover the granular meta-data components or sub-components, there by each decision elements in the code can be scanned to measure the complexity \& quantify appropriately [9]

Algorithm states -. In a program for a method / function start with the count as one.

For every granular programming statements in the method/function, add one for each

\section{Category Add one for each of the following}

Returns Each return that is not the last statement of a method.

Selection if, else, else-if, default, case

Loops do-while, for, break, while and continue.

Operators $\quad \& \&, \|$, and:

Exceptions Catch, finally, throws clause.

Complexity of a class is the highest complex function in the class.

A refined complexity algorithm catering to COTS and other latest technology advancement has been developed through this research to incur any library functions being invoked, any standard utility being reused, etc. The count can be incremented for each of the remote method invocation.

A McCabe complexity under 25 is good, from $25-50$ is OK, and over 50 is too complex. A high flow complexity may be a symptom of a function which does too much or has low cohesion (does too many different things). Lower is Better!

The Tool has been developed with above algorithm can further been extrapolated to plug into CRM or Open-source applications based on Simple object access protocol (SOAP) invocation principles. The meta-data can be extracted and parsed using the tool to derive the complexity score for all customizations. The entry points are designed to be User Interface (UI), Trigger and other Event- or User- driven entry point. The parsed code is logically constructed as an output in Comma separated values (CSV) file as shown in below diagram. The CSV file can further be fed to generate a Flow-chart or data-flow kind of Unified modelling language (UML) diagram to arrive at UI model. 


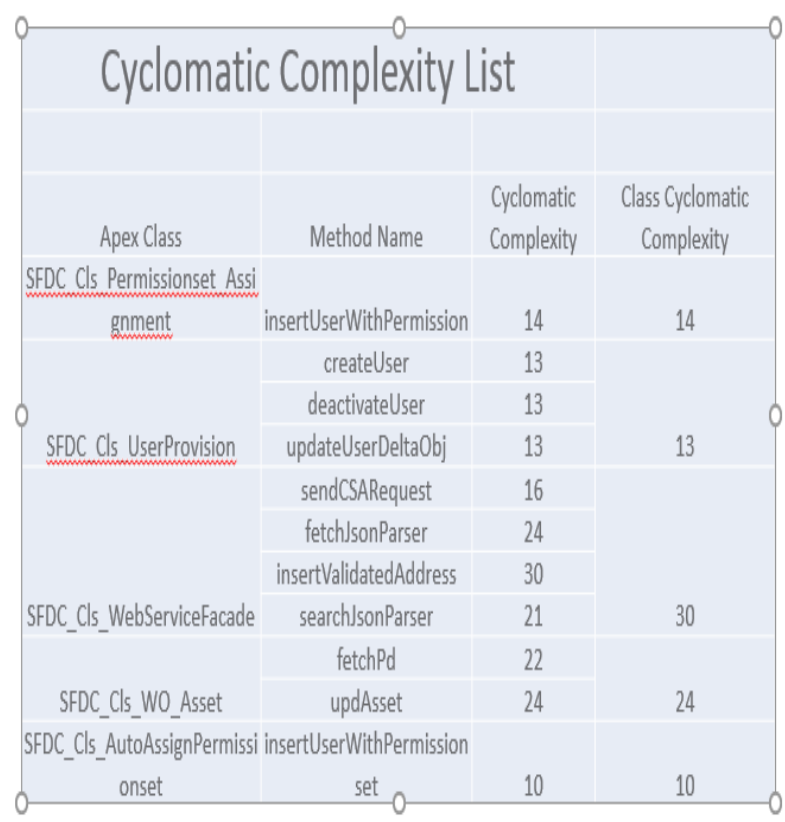

Analysis

We have chosen a cloud based CRM implementation for our case study

1. KT planning

2. Initial assessment of the application

3. Inventory assessment

4. Impact analysis

Above listed processes are absolutely required when we take up large organizations where we need to analyze and build a due diligence / system appreciation in a short duration

The cyclomatic complexity analysis output can be further fed to construct a simple flow chart to give the big picture to the team in understanding the interdependencies. As defined by 11 Baccarani - Project complexity is a multiple factor of interdependencies.

Further mapping complexity score with skill-competence domain as below:

Below table shows how key complexity levers in IT project delivery could be addressed: Cyclomatic complexity score in conjunction with category can determine the skill-set needed, story points or estimated person days to understand and enhance the application. The score directly implies the skill-set level (1 to 5) of the staffed resource. There by covering breadth and depth in the estimation and paves way for appropriate staffing (Skill competency scale reference model [9]).

\begin{tabular}{|l|l|l|l|}
\hline Domain & $\begin{array}{l}\text { CC } \\
\text { score }\end{array}$ & $\begin{array}{l}\text { Skill } \\
\text { sub-domain }\end{array}$ & $\begin{array}{l}\text { Skill } \\
\text { depth } \\
\text { needls } \\
(1-5)\end{array}$ \\
\hline UI & $>35$ & $\begin{array}{l}\text { Page layouts, } \\
\text { Visual force } \\
\text { paging, CSS, } \\
\text { Advanced } \\
\text { bootrsap, GUI } \\
\text { elements }\end{array}$ & 4 \\
\hline Configuration & NA & $\begin{array}{l}\text { COTS skill } \\
\text { (point-and-click } \\
\text { features) }\end{array}$ & $\begin{array}{l}\text { Average } \\
\text { Avar }\end{array}$ \\
\hline
\end{tabular}

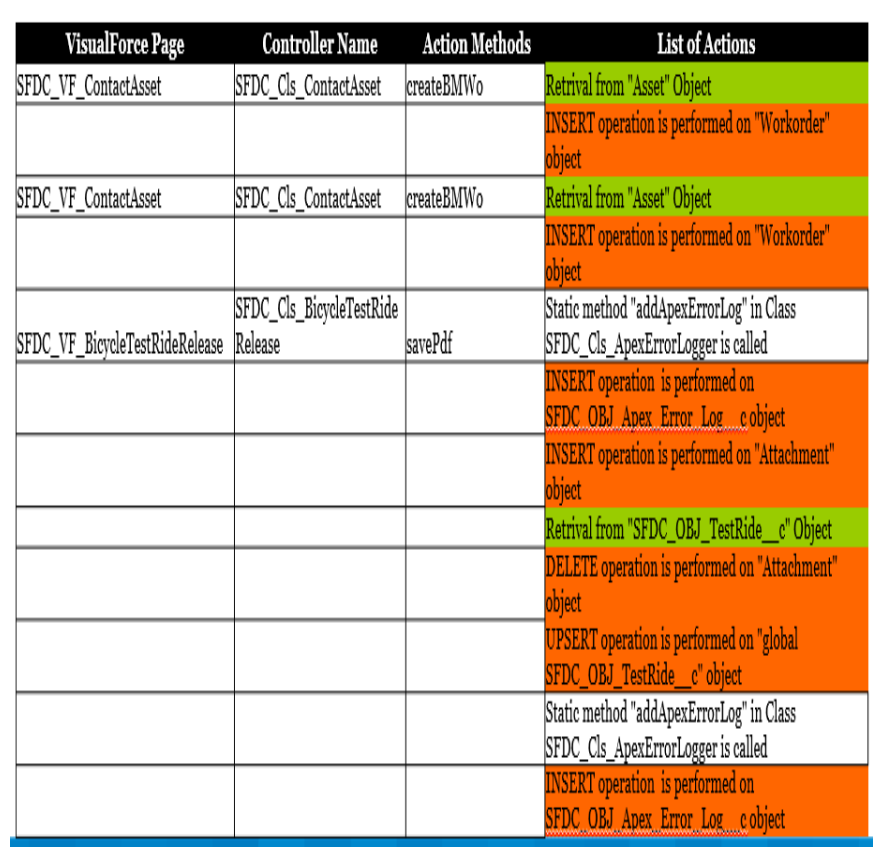

Fig - 4: Sample Cyclomatic complexity for a project under study

\begin{tabular}{|c|c|c|c|}
\hline Customization & $<10$ & $\begin{array}{l}\text { Class } \\
\text { Trigger } \\
\text { Component } \\
\text { development } \\
\text { Scripting } \\
\text { Etc. }\end{array}$ & 2 \\
\hline Integration & $>50$ & $\begin{array}{l}\text { Soap, Rest, } \\
\text { OData, SAML, } \\
\text { Batch }\end{array}$ & 5 \\
\hline Security & $>20$ & $\begin{array}{l}\text { Profiles, Roles, } \\
\text { Access } \\
\text { permissions, } \\
\text { Network } \\
\text { settings, Proxy, } \\
\text { Security } \\
\text { Gateway, } \\
\text { Sharing rules }\end{array}$ & 3 \\
\hline $\begin{array}{l}\text { Non Functional } \\
\text { Requirement } \\
\text { (NFR) }\end{array}$ & NA & $\begin{array}{l}\text { Performance } \\
\text { Scalability } \\
\text { Availability } \\
\text { Reliability } \\
\text { Maintainability } \\
\text { Capacity } \\
\text { Recoverability, } \\
\text { so on }\end{array}$ & $\begin{array}{l}2.5 \\
\text { Average }\end{array}$ \\
\hline
\end{tabular}

Tab - 3: Cyclomatic complexity to Skill-depth mapping considering Sub-domain as per Technology

\section{Results}

Front end with your good people.

Project complexity is predominantly affected based on existing AS-IS system and technology stack; the customization is hard to quantify which is where Cyclomatic complexity assessment helps in quantifying and simplifying the overall picture to help staff the right level of skills. Our experiment proves our original problem statements

[1] \& [2] as defined under study design of this research work.

Published By:

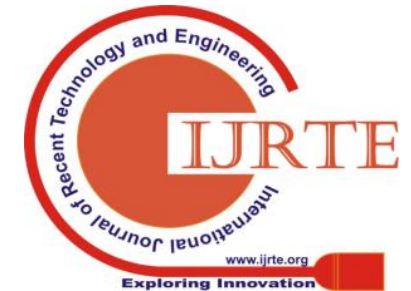




\section{Elevate Project Success Rate with Right Judgement of Complexity and Skill Competency Gap}

Further Cyclomatic complexity helps in several inferences such as:

1. Grouping of related / interdependent classes or code under a Module or Capability - align a team lead to manage the code.

2. Create teams based on inter-dependent classes, there by increased collaboration in the team

3. Align right level of experienced professional to handle a given set of classes falling under certain cyclomatic score and similar pattern

4. Based on the score - project manager can prioritize which customized module should be given more focus and attention (Referred in study design problem statement III)

5. Team can prioritize which customization bucket to be tackled first and bandwidth can be given accordingly.

6. Finally, the project where a team identifies the right level of attention to most complex areas in the overall project itself guarantees halfway success.

Other factors affecting the Project complexity, and are out of scope of our research study, are

1. Complexity of KPIs itself.

2. Complexity of Business functions and process

3. Complexity due to changing roadmap of customer

4. Green-field project implementation with fresh new architecture and requirements

5. Complexity arising due to other SDLC levers such as poor requirement engineering, incorrect or short-term architecture, deployment or testing, etc.

\section{PROBLEM STATEMENT (Phase 2)}

As conversed at the start of this paper, phase 2 of our research activity tries to address the feasible solution to derive skill-capability index, which can elevate the project success rates, which is undermined due to estimation factors relating to project complexity. Absence of skill-matrix index and suitable metric to measure right team for a given $\mathrm{SAFe}$ project has been a present challenge.

\section{RESEARCH METHODOLOGY (Phase 2)}

Four Essential Components for Skills Inventory Management [16]

1. A Well-defined Classification System

2. A Consistent Unit of Measure

3. An Efficient Measurement Process

4. A Practical Tracking and Reporting System

The Skill Matrix Index can be visualized as a central repository of competency data that represents the skill set of all the team members at Project, Program, Portfolio or Practice level and serves as a platform to enable "Skill Based" Resource Management for better management of projects and large programs with horizontal and vertical based reuse of skilled resources.
The primarily parameters to assess competency are technology, domain and process skills of the employees in the organization

o Extracting skill data from existing information systems and o Skill Data manually entered by employees and further reviewed and approved by Supervisors

- Online competency test results to assess employee uniformly.

For Employees:

The Skill Central application provides a systematic mechanism for capturing, ascertaining, and enabling periodic updates of employee skills hence giving every employee a chance to be identified for a project requiring specific skill sets and experience level.

For Managers:

The Skill Matrix Index increases the visibility of employee availability with the required skill set enabling skill tracking and smooth resource allocation. The skill repository can be queried to identify the right employee based on the skill requirement and appraisal findings competency can be extended to cover the soft-skill aspects such as Communication, Attitude, Flexibility, Thought leadership, Pro-activeness, learnability, mentoring ability and so on.

\section{Tab-4: Skill-capability matrix of a department}

\begin{tabular}{|l|}
\hline Currently Working on? \\
\hline Set Primary Skill \\
\hline Skill Description \\
\hline Project Id (s) \\
\hline Experience in Month(s) \\
\hline Last, Worked on? Interested to work again on similar project? \\
\hline Certifications, Trained or Mentored? \\
\hline Any Knowledge articles published \\
\hline
\end{tabular}

Skill proficiency chart for a given specialized technology or industry domain shall help practice/department to obtain a bird's-eye view of the entire Skill Dictionary on the first and second skill layers. The Skill Dictionary is divided into five categories based on the skill characteristics: methodology, technology, related knowledge.

Fig - 5: Competence scheme for skill-depth mapping

\begin{tabular}{|l|l|l|l|}
\hline Competence Level & \multicolumn{1}{|c|}{ Methodology } & \multicolumn{1}{|c|}{ Technology } & Domain/ Related Knowledge \\
\hline Level 1 & $\begin{array}{l}\text { Understands theoretically; have } \\
\text { been trained }\end{array}$ & $\begin{array}{l}\text { Trained in basic software } \\
\text { programming and project delivery } \\
\text { methodologies }\end{array}$ & $\begin{array}{l}\text { Can explain basic jargons of the } \\
\text { industry; understands L1 level of } \\
\text { business process }\end{array}$ \\
\hline Level2 & $\begin{array}{l}\text { Able to apply concepts under } \\
\text { guidance }\end{array}$ & $\begin{array}{l}\text { Has been exposed to industry } \\
\text { projects \& can apply technology } \\
\text { under guidance and monitoring }\end{array}$ & $\begin{array}{l}\text { Understand the IT - busines } \\
\text { process interaction to L2 level of } \\
\text { process }\end{array}$ \\
\hline Level3 & $\begin{array}{l}\text { Is able to contribute in marketing, } \\
\text { pre-sales and other IT levers with } \\
\text { the TT accumen and subject matter } \\
\text { expertise. }\end{array}$ & $\begin{array}{l}\text { Is able to work independently } \\
\text { under limited circumstances }\end{array}$ & $\begin{array}{l}\text { Able to map IT solutions to } \\
\text { Business problems, and has } \\
\text { exposure to best practices }\end{array}$ \\
\hline Level4 & $\begin{array}{l}\text { Brings 0ptimal solution, Industry- } \\
\text { wise reuse, automate repeated } \\
\text { problems }\end{array}$ & $\begin{array}{l}\text { Has mastered multiple technical } \\
\text { levers and multiple platforms. Able } \\
\text { to seamlessly apply solution to the } \\
\text { problems }\end{array}$ & $\begin{array}{l}\text { Brings in best practices and able to } \\
\text { debate and work-out alternate } \\
\text { solution options for the industry } \\
\text { problems }\end{array}$ \\
\hline Level5 & $\begin{array}{l}\text { Center of Excellence member to } \\
\text { derive strategy and long-term goals }\end{array}$ & $\begin{array}{l}\text { IT Governance, Strategize and } \\
\text { intervene to guide the teams and } \\
\text { adopt methodology }\end{array}$ & $\begin{array}{l}\text { Deep exposure to industry } \\
\text { evolution and can map well with IT } \\
\text { needs time to time. }\end{array}$ \\
\hline
\end{tabular}

SFIA - Skills framework for the information age foundation identifies seven 
levels and are used to provide generic levels of responsibility and to reflect experience and competency.

FOLLOW $>$ ASSIST $>$ AAPLY $>$ ENABLE $>$ ENSURE $>$ INFLUENCE $>$ ST RATEGY

The definitions describe the behaviors, values, knowledge, and characteristics that an individual should have in order to be considered competent at a particular level [13]

Similarly, European competency framework uses five e-competency proficiency levels around below themes

PLAN-> BUILD->RUN->ENABLE->MANAGE

Competency Upliftment approach recommended based on our research are as below:

- Machine Learning driven Recommendations

- Connections and Collaborations

- Connect with Mentors

- Training plan (Internal / External / Certification) and milestones

- Best fit Projects with location and current status and highlight further gaps in skills before onboarding

- Set goal of one or two knowledge article contribution with fair deadline (half-yearly or quarterly)

- Involve in Mini-Project or Internal Project for Hands on experience and capability building

- Knowledge transfer of Project overview, expectations of the Role and readiness timeline

In an ever-changing world, in order to be ahead of the curve, each one of the team member has to continuously learn while doing daily job (Leadership team shall imbibe the learning culture into the DNA of Organization).Provide varieties of learning opportunities through classroom training, blended learning, learning through VCRs, self-learning using Learning Platform, Digital Tutor sources (Multi-media based - video SME, TED-Talk) and appropriate external MOOCs, while Organization continuously improve upon the same.

Individual learning should be driven by the business need, manager's recommendation (as part of IDP) \& the individual's aspiration, and not driven by compliance requirements.

Assessments are designed to assess the effectiveness of training and aligned to the learning objective of each training capsule

The external certifications and some of the internal certifications (as chosen by business units) will continue to stay and employees can opt for it based on their manager's recommendation or as per the individual's need. Learning credit points associated

Competency Anchors and Mentors enabling mechanisms available at Practice/Department/Service offering level:

○ Instructor Led Training - Classroom sessions are held at different locations. Refer to trainings lab in Learning.

o Virtual Classroom: Virtual classroom trainings are scheduled for some of the technical certifications using tools such as AT \& T Connect (Interwise)

○ E-learning: E-Learning, Digital Tutor, Learning Platform (LP) courses are available for many of the Technical Certifications. They allow team members to learn the modules at own pace

Enhancing the quality of the learning content must be one of the foremost objectives of the holistic competency development framework. Employees across roles and departments must have a desire for an enhanced learning content and the need to leverage partnership for external content. Form the Competency Task Force, and leverage partnership with external providers (like Microsoft, Oracle, Harvard Publishing, etc.) and use external content to bring in a richer learning experience.

As a blended model, that is a combination of in-house learning content (in the form of presentation slides) along with external learning content through reference links.

\section{RESULTS}

Cross-skill equation has ensured lesser escalations in large transformation programs due to end-to-end understanding of IT landscape.

One of the Surveyed Organization took up below approach around skill-enablement programs to achieve cross-skills.

- Re-skilling talents (Front-End technology resources train on Node JS), (Back-End technology resources train on Angular JS)

- Enable team on Test Driven Development (TDD)

- Enable team on Behavior Driven Development (BDD)

Median score has helped in identifying the Quarter on Quarter improvement, and further scale it to Year-on-Year.

Looking at above table 3 results derived from a sample Program (either per project or per program or per practice) the skill-capability matrix will give the report on skill category and depth as a monthly snapshot, a quick Mean, Median and Mode derivation shows that

Mean skill-set for a given month $=\sum(\mathrm{N} 1+\mathrm{N} 2+\mathrm{N} 3+\ldots \ldots$ $\mathrm{Nn}) / \mathrm{n}$

Arranging the skill-set depth in ascending order and then if number of employees are Even, then Median could be derived by $n / 2$ else $(n+1) / 2$

The median is the middle value which indicates, if the median value in a scale ( 1 to 5 ) is more towards 5 , that indicates practice has highly skilled and deep-skilled individuals which is a good sign either in terms of bench strength, or well-staffing readiness for any upcoming project.

On the other hand, if Median values is more towards lower scale (in 1 to 5), this is an indication of immediate training, upskill needed for majority of the resources and this is an alarming state for practice heads or delivery management.

Finally, Mode is derived - 'Mode is the number that is repeated more often than any other' in our experiment mode is ' 4 ' which means we have healthy number of high skilled or deep-skilled individuals. On the other hand- if mode is on lower end this is a reflection of poor skilled team or practice which needs intervention.

In summary, Median and Mode values reflect the quantification of current state of skilled resources month on month, which can be easily extrapolated to Quarter, half-year or yearly numbers. The increase in Median or Mode each month reflects a good state of knowledge centric organization process. If a median / mode is constant or falls flat in spite of training and upskill and mentoring interventions - this is an indication of other external factors such as Attrition, Attitude, de-motivation, so on.

Estimating the right team for the given project complexity involves baselining the skill-set need as per Phase 1 results, and mapping with the practice level skill-capability index mapping as discussed in phase 2 above. There are many other factors such as Attrition, Unavailability, location constraint, attitude, leave plans

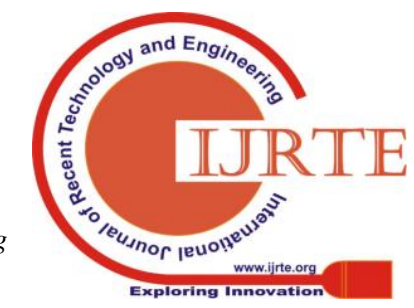


and many more that will still affect the optimal mapping exercise, these practical challenges will continue to exist and shall be dealt through soft-skills and other team nurturing interventions.

Pareto Analysis over the stability of the team was found to be at an average of $80 \%+$ which is a remarkable level in large programs when team staffing is applied based on Project complexity score findings by Light-house team and adopting the skill-index matrix recommended in this paper.

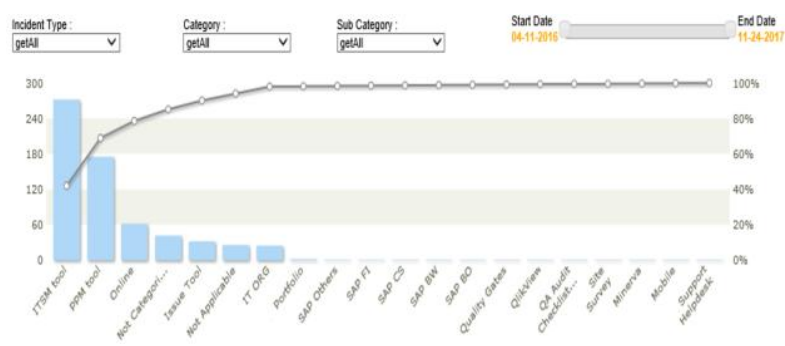

Fig - 6: Pareto-Analysis reflecting stability of projects resulting from complexity based staffing model

\section{DISCUSSIONS}

Skill-capability based project allocation alongside project complexity mapping was piloted on two projects under our study scope. Below results were observed and documented

\section{Better business value}

Deliverable quality improved across all stages of software delivery alongside achieving higher business value due to right first time. Major improvement was observed around knowledge transition confidence index, the cost associated with logistics and team setup was drastically down by $30 \%$..

\section{Customer satisfaction due to elevated project success}

In present market scenario, customers are operating on zero cost knowledge transfer and projects are allocated or contract is signed only with the fruitful knowledge transfer and scoring during the shadow and primary support. Cost optimization with right width-depth understanding of client systems is key in today's procurement scene.

A $5 \%$ increase in client satisfaction or at engagement level feedback can lead to repetitive business and trust entrusted on implementation partner.

As of the Experiment so far, the measurement has been so far fruitful in terms of knowledge transfer and contract signing aspect, the team on ground is aptly placed to tackle the upcoming challenges. Further extension of the team is based on the monthly KPIs and other performance indication. The key to win a client and start with good confidence is derived through cyclomatic complexity based Estimation model in conjunction with well-maintained skill-capability matrix to map the right skilled personnel to the right project.

It often happens that outgoing vendor or external contractors or professional services shall be engaged to carry on with the project; the skill-matrix will help to scientifically measure the skill-depth of the internal resource to decide the right time to replace the external sub-contractor and thereby help organization achieve the cost goals or increase the margins or reduce the operational cost.

Other long term benefits of Skill capability matrix are

- Develop succession plans and learning path

- Plan for staff professional development

- Develop training programs

- Develop performance management expectation
- Knowledge gap risk cover thus ensuring higher rate of project success

\section{X . CONCLUSION}

Project management is plagued by several internal and external factors today. While Agile methodology seem to have achieved best results in balancing the aspirations of both the business and IT community and elevated project success rates compared to old delivery methods, absence of few best practices guidelines in Agile plus certain practices existing in the software integrators has led to project failures. This paper limits its scope of problem statement specifically around understanding the scope, complexity of AS-IS / TO-BE systems so that right skilled staffing is accounted for, there are many other point of failures such as vague requirements, poor designs, etc. which could be a research area for future researchers. The quantification technique discussed in this paper were found practical and adoptable as a best practice in the project delivery cycles at very early stages to de-risk incorrect judgements about the size and complexity of work in hand. The skill-competence index suggested in this paper was also found to be crucial for knowledge centric organization evolution to achieve long-term sustainability and survivability.

\section{REFERENCES}

1. Ranjana Rajanish, "Writing Quality Requirements(SRS): An Approach to Manage Requirements Volatality"Indian Journal of Computer Science and Engineering,Vol1,No1,pp28-37 ISSN:0976-5166

2. Standish group international: The chaos report (1994), http://www.standishgroup.com/sample-research/choas-1994-1php,19 94

3. Shubhamangala B.R 1, Manjunatha Rao .L2, Anandan Dakshinamurthy 3, Chandrika Good Luck Singh " Ability Based Domain Specific Training: A Pragmatic Solution to Poor Requirement Engineering" Conference Paper . May 2012 DOI 10.1109/CSAE.2012.6272993

4. Dagez "Applying neural network technology in qualitative research for extracting learning style to improve e-learning environment" appearing in IEEE International symposium on Information Technology ITsim2008, pages 1-6

5. Li Ming, Yang Nan" Research on the Evaluation system of IT Project", appeared in International Conference on Computational Intelligence and Software Engineering, 2009,Pages 1-4

6. Sharifi Mohammad "Lessons learned in ITIL implementation failure" appearing in IEEE International symposium on Information Technology ITsim2008.

7. Brain ,Nancy L.Russo "Software development method tailoring at Motorola" Published in Communications of ACM, Volume 46, Issue 4, April 2003, pages 64-70, ISSN: 0001-0782

8. McCabe, T. J., "A Complexity Measure," IEEETransactions on Software Engineering, vol. 2, no. 4, pp.308-320, 1976

9. https://pprg.stanford.edu/wp-content/uploads/1997-Designing-ratingscales-for-effective-measurement-in-surveys.pdf

10. https://www.leepoint.net/principles_and_practices/complexity/compl exity-java-method.html

11. http://www.statstutor.ac.uk/resources/uploaded/wilcoxonsignedrankte st.pdf

12. http://eitbokwiki.org/Enterprise_IT_Skill_Frameworks

13. https://www.pmiwdc.org/sites/default/files/presentations/201703/PMI W_LocalCommunity_Tysons_presentation_2017-02.pdf

14. https://www.computer.org/ieeecs-swebokdelivery-portlet/swebok/SW ECOM.pdf 


\section{AUTHORS PROFILE}

Thejasvi N, Department of Computer Science \& engineering, Jain University Bengaluru India, has Bachelor's degree in Information Science and Master's degree in Telecommunications. He is currently pursuing Ph.D. in Computer Science and Engineering with areas of interest being Application

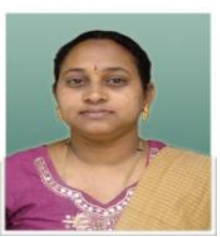

Shubhamangala $\mathbf{B} \mathbf{R}$ is a researcher in software firm with particular intrests in data science,Data analytics,Application security, Security requirements , Compliance and risk. She has authored paper in the domain of product quality, requirements and application security. She has authored a publication in ASQ-SQP journal and many of her papers are indexed in IEEE exp[lore data base.She holds a bachelor and master degree in CS.She is member of IEEE. 